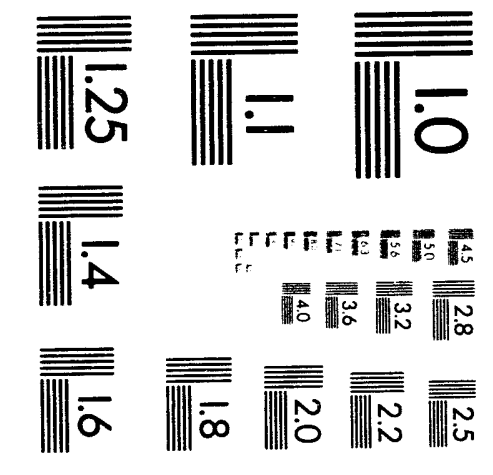



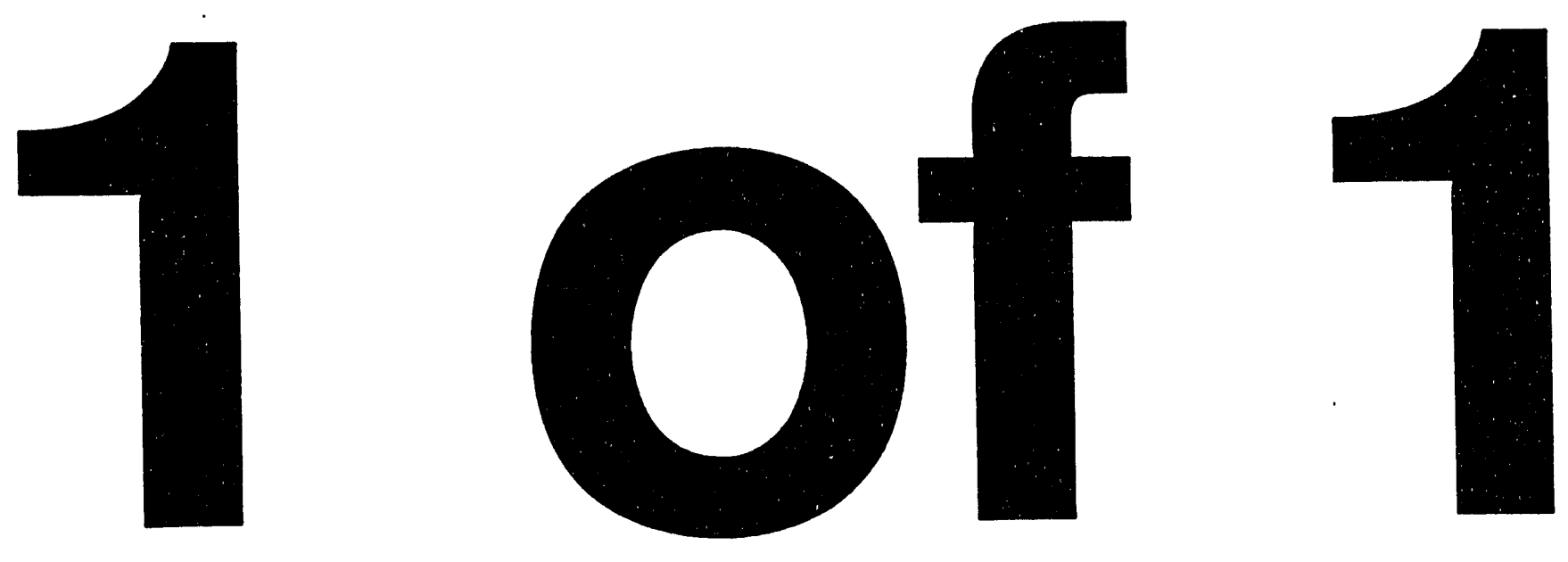


\title{
HEB Spool Pieces Design Description
}

\author{
D. Clark and D. Strube \\ Superconducting Super Collider Laboratory* \\ 2550 Beckleymeade Ave. \\ Dallas, TX 75237
}

February 1994

*Operated by the Universities Research Association, Inc., for the U.S. Department of Energy under Contract No. DE-AC35-89ER40486. 


\title{
HEB Spool Pieces Design Description
}

\author{
Donald Clark and Doug Strube
}

\begin{abstract}
The many varied types of spool pieces for the High Energy Booster (HEB) of the Superconducting Super Collider (SSC) Laboratory are presented. Each type of spool piece is discussed, and the specific components are identified. The spool piece components allow each spool piece to perform as a unique electromechanical device positioned in series with large superconducting magnets to provide electrical and mechanical support for each superconducting magnet in areas of cryogenics, electrical power, instrumentation, diagnostics, and vacuum. A specialized HEB superspool is identified that perhaps has the potential to aid in the overall configuration management of the HEB lattice by combining HEB superconducting quadrupole magnets and spool pieces within a common cryostat.
\end{abstract}




\subsection{INTRODUCTION}

The two spool pieces for the standard arc cell of the Superconducting Super Collider (SSC) High Energy Booster (HEB) : e assembled with a series of four dipole magnets and two quadrupole magnets forming a 65-m-length cell. The two standard arc spool pieces that normally alternate in position are the spool pieces that contain a physical barrier (SPXA), which isolates the vacuum of one cell from any other cell, and the spool pieces, which contain a heat exchanger that allows the temperature of the liquid helium to be controlled as the helium is circulated through the magnets (SPRA). There are seven additional spool pieces identified throughout the HEB. Based on the location of these specialized spool pieces, they provide unique functions within the HEB lattice. The list of spool pieces identified for the HEB are listed in Table 1.

TABLE 1. HEB SPOOL PIECES. ${ }^{1}$

\begin{tabular}{|l|l|c|}
\hline \multicolumn{1}{|c|}{ SPOOL PIECE } & \multicolumn{1}{|c|}{ NOMENCLATURE } & SLOT LENGTH \\
\hline SPXA & Standard Spool Piece without Recooler (X) for HEB ArC & $3.675 \mathrm{~m}$ \\
SPRA & Standard Spool Piece with Recooler for HEB Arc & $3.675 \mathrm{~m}$ \\
SPRE & Standard Spool Piece with Recooler and Cryogenic End & $7.350 \mathrm{~m}$ \\
SPRF & Standard Spool Piece with Recooler and Cryogenic Feed & $7.350 \mathrm{~m}$ \\
SPRI & Standard Spool Piece with Recooler and Cryogenic Isolation & $7.350 \mathrm{~m}$ \\
SPR31 & Spool Piece with Recooler and 3 m of length for Cryogenic Isolation & $3.675 \mathrm{~m}$ \\
SPR4T & Spool Piece with Recooler and 4 m of length for Cryogenic & $4.675 \mathrm{~m}$ \\
SPX1R & Transition & $1.000 \mathrm{~m}$ \\
SPX1T & Spool Piece without Recooler (X) and 1 m of length for Cryogenic & \\
Superspool & Return & $1.000 \mathrm{~m}$ \\
& Spool Piece without Recooler (X) and 1 m of length for Cryogenic & \multirow{2}{*}{ Transition } \\
SPXA with a HEB Quadrupole Magnet incorporated within a & $6.158 \mathrm{~m}$ \\
\hline
\end{tabular}

\subsection{DISCUSSION}

The specific requirements ${ }^{2}$ by definition and performance of each spool piece may be found in the Element Specification (Level 3B) for the HEB Accelerator of the SSC Laboratory, Number E10-000054. The discussion that follows identifies major components of SPXA and SPRA spool pieces and presents a cursory review of component function.

The spool piece has a stainless steel tube designed to contain the proton beam when the HEB is operational. This beam tube provides an aperture that allows for beam size, beam orbit, and beam misaiignment. Also, the beam tube provides the boundary for the ultra high vacuum necessary for the proton beam to be transported with a minimum of nuclear scattering of gas molecules. This beam tube is positioned within cryopipe \#1, also known as the coldmass. Cryopipe \#1 is designed to circulate 4-K helium, which is employed to cool superconducting magnets. The spool piece may contain correction elements in the form of smaller superconducting magnets (i.e., quadrupole, sextupole, dipole) that are designed to be housed within cryopipe \#1 and the 4-K helium circuit to implement beam correction. There are five additional cryogenic lines or cryopipes that are designed to circulate 4- $\mathrm{K}$ helium, 20-K helium, and $80-\mathrm{K}$ nitrogen. Four of these cryogenic circuits are moderately pressurized. Each of these six cryogenic circuits may contain system control valves and relief valves that are housed within or attached to flanges built within the spool piece. The cryopipes are wrapped in Multilayer Insulation (MLI) to assist in thermally isolating each of the cryogenic systems. 
The beam tube at the lead end of the spool piece is attached to the beam diagnostics instrument known as the beam position monitor (BPM), which is able to detect electrically the position of the proton beam while the protons are circulating through the beam tube.

Cryopipe \#1 also has an electrical device designed to function similarly to a diode. This device, known as the quench stopper, is designed to redirect the flow of electrical current from the superconducting magnets during magnet quench to an outside electrical circuit via the bypass leads. The quench stopper and bypass leads are designed to limit the temperature increase in any magnet system and thus to prevent damage to any superconducting magnet. The superconducting electrical bus is routed through cryopipe \#1 and is attached electrically to the quench stopper.

In order for the circulating 4-K helium to maintain optimal temperature, there is a heat exchanger positioned within the SPRA, identified as the spool piece recooler. The recooler operates by expanding 4-K helium supplied from cryopipe \#1 via a recooler valve against a 4-K helium bath and returning the colder helium to cryopipe \#1.

All of the components and systems described that make up the internals of the spool piece are housed within a stainless steel outer vacuum vessel. This outer vessel or cryostat provides the boundary for the insulating vacuum. The installation of spool piece types alternate within the $65-\mathrm{m}$ cell of the HEB lattice. Spool pieces fabricated with the addition of recoolers and quench stoppers with bypass leads are designated as SPRA. Spool pieces that do not contain these components but have internal physical barriers identified as vacuum barriers such that cell isolation can be achieved for vacuum operations during cell evacuation are designated as SPXA.

\subsection{Standard Spool Piece without Recooler for HEB Arc (SPXA)}

The SPXA provides a connection system for power, cryogenics, vacuum, instrumentation, and controls for the HEB components. The SPXA includes cryogenic enclosures, insulating vacuum, beam tube, BPM, external connections, and corrector element magnet package. The SPXA provides vacuum isolation by means of the vacuum barrier. There are 141 SPXA positioned within the HEB lattice. Figure 1 is a schematic of the SPXA. The components necessary for the fabrication of the SPXA are listed in Table 2.

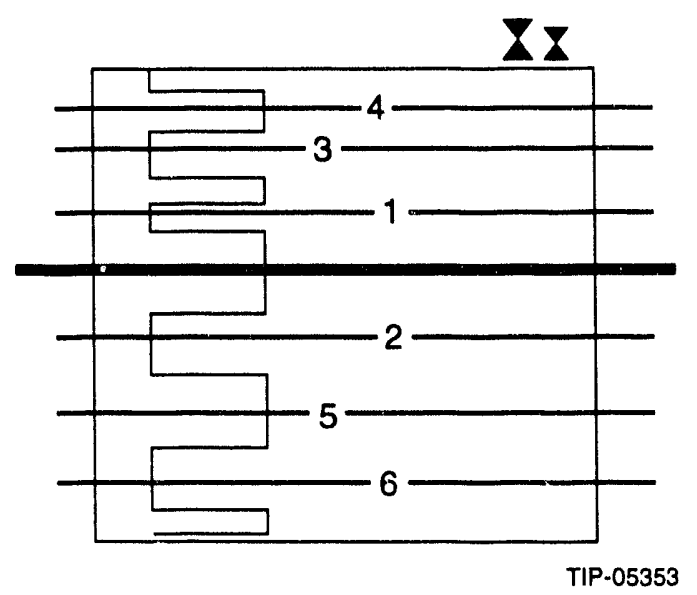

Figure 1. A schematic of the SPXA, with cooldown and warm-up valve, quench valve, and vacuum barrier. 
TABLE 2. SPXA COMPONENTS.

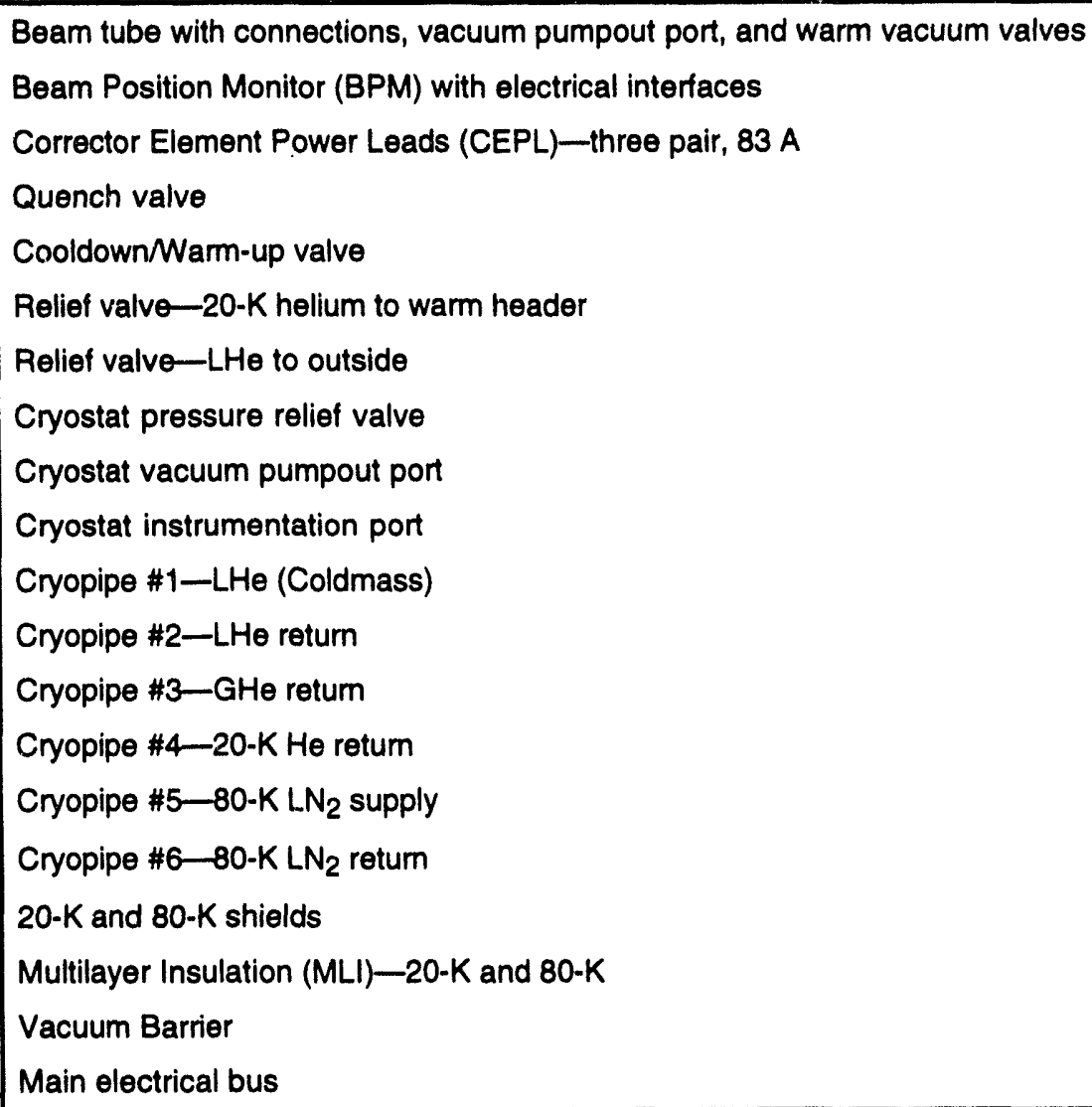

\subsection{Standard Spool Piece with Recooler for the HEB Arc (SPRA)}

The SPRA provides a connection system for power, cryogenics, vacuum, instrumentation, and controls for the HEB components. The SPRA includes cryogenic enclosures, insulating vacuum, beam tube, beam position monitor, external connections, and corrector element magnet package. The SPRA provides the magnet quench protection system (quench stopper and bypass leads) and liquid temperature control (recooler). There are 143 SPRA positioned within the HEB lattice. Figure 2 is a schematic of the SPRA. Components of the SPRA are listed in Table 3. 


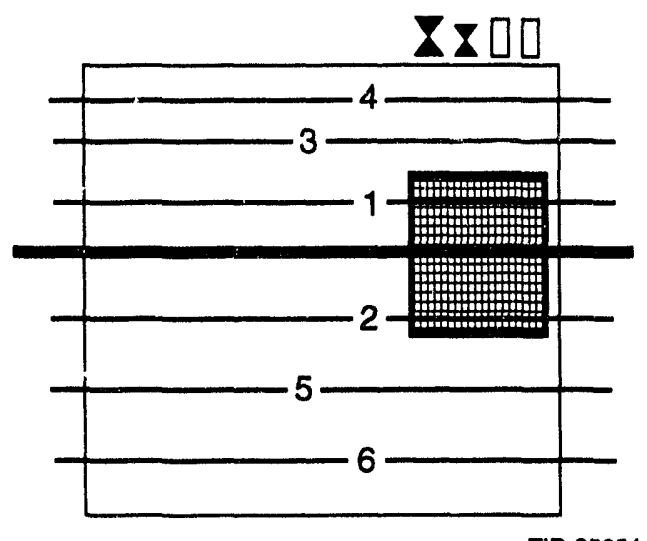

Figure 2. A schematic of the SPRA, with cooldown and warm-up valve, quench valve, recooler, and bypass leads.

TABLE 3. SPRA COMPONENTS.

Beam tube with connections, vacuum pumpout port, and warm vacuum valves

Beam Position Monitor (BPM) with electrical interfaces

Corrector Element Power Leads (CEPL)-three pair, $83 \mathrm{~A}$

Quench Stopper with Bypass Leads

Quench valve

Cooldown/Warm-up valve

Relief valve-20-K helium to warm header

Relief valve-LHe to outside

Cryostat pressure relief valve

Cryostat vacuum pumpout port

Cryostat instrumentation port

Cryopipe \#1-LHe (Coldmass)

Cryopipe \#2-LHe return

Cryopipe \#3-GHe return

Cryopipe \#4-20-K He return

Cryopipe \#5-80-K $\mathrm{LN}_{2}$ supply

Cryopipe \#6-80-K $\mathrm{LN}_{2}$ retum

$20-\mathrm{K}$ and $80-\mathrm{K}$ shields

Multilayer Insulation (MLI)-20-K and 80-K

Recooler Assembly

Recooler Valve

Main electrical bus 


\subsection{Standard Spool Piece with Recooler and Cryogenic End (SPRE)}

The SPRE provides a cryogenic turn around capability and return of the cryopipes to the cryogenic plants. The SPRE is the end of a string section and contains two separate halves, each of which may contain corrector element magnet packages. The SPRE also contains liquid temperature control (recooler) on each half of cryopipe \#1 and includes in each half: cryogenic enclosures, insulating vacuum, beam tube, quench stopper, bypass leads, and external connections. The beam position monitor is located on the lead end, and the main magnet energy is designed to enter and exit at the SPRE also. There are two each SPRE positioned within the HEB lattice; the locations are $\mathrm{H} 40$ and H80. Figure 3 is a schematic of the SPRE. Components of the SPRE are listed in Table 4.

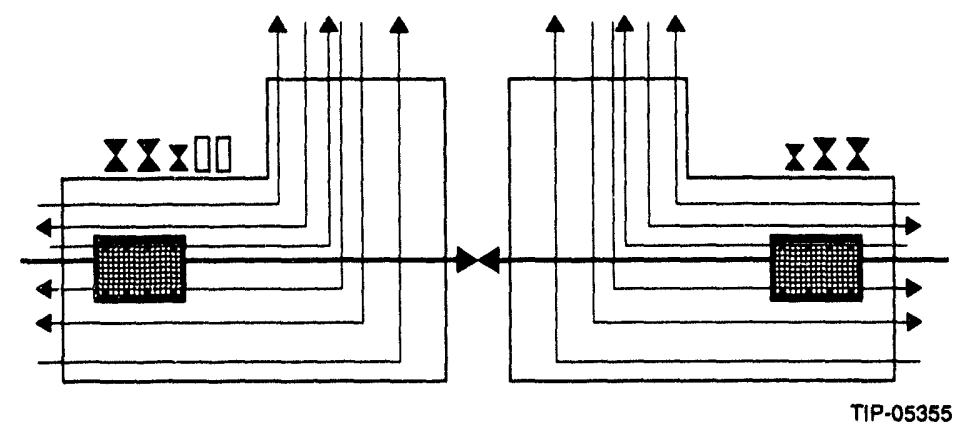

Figure 3. A schematic of the SPRE, with cooldown and warm-up valve, quench valve, recooler, and bypass leads.

TABLE 4. SPRE COMPONENTS.

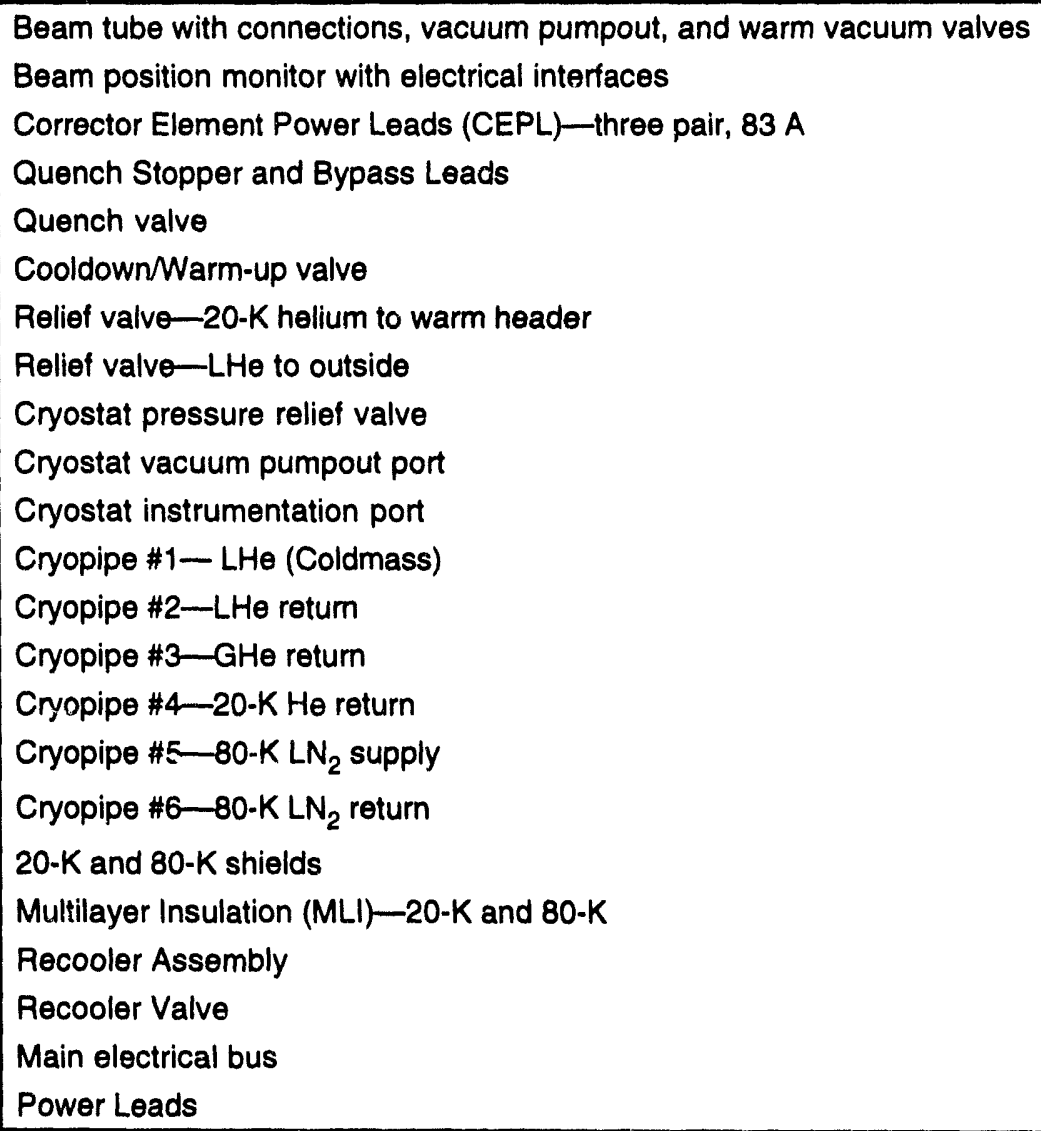




\subsection{Standard Spool Piece with Recooler and Cryogenic Feed (SPRF)}

The SPRF provides cryogenic feed capability and is the cryogenics interface with the refrigeration plants. The SPRF is the start of a string section and contains two separate halves, each of which may contain corrector element magnet packages. The SPRF also contains liquid temperature control (recooler) on each half of the cryopipe \#1 and includes in each half: cryogenic enclosures, insulating vacuum, beam tube, quench stopper, bypass leads, and external connections. The beam position monitor is located on the lead end, and the main magnet energy is designed to enter and exit at the SPRF also. There are two locations for the SPRF within the HEB lattice; the locations are H20 and H60. Figure 4 is a schematic of the SPRF. Components of the SPRF are listed in Table 5.

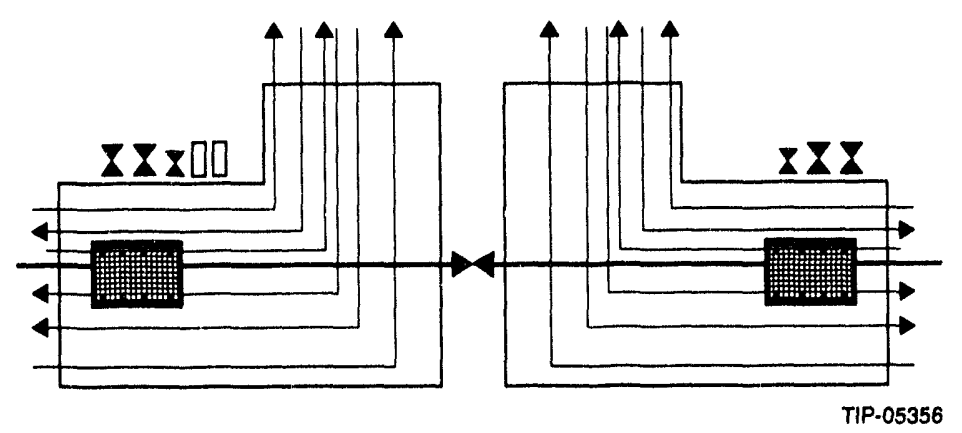

Figure 4. A schematic of the SPRF, with cooldown and warm-up valve, quench valve, recooler, and bypass leads.

TABLE 5. SPRF COMPONENTS.

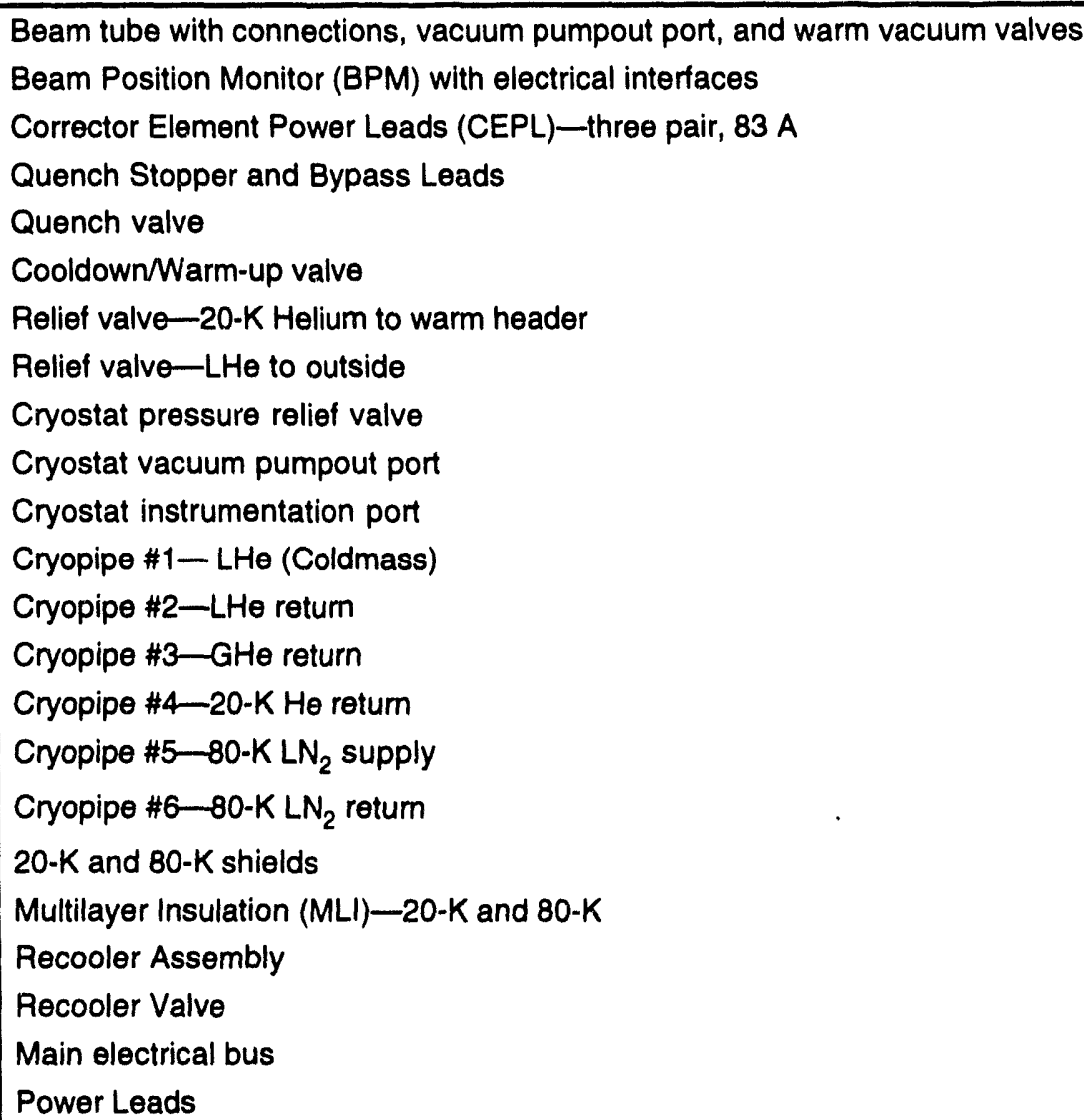




\subsection{Standard Spool Piece with Recooler and Cryogenic Isolation (SPRI)}

The SPRI provides cryogenic and vacuum isolation; also designed within the SPRI is turnaround capability of the cryogenics for each string via the cryogenic bayonets. The dividing of the string allows for two distinct cryogenic sections. The SPRI also contains liquid temperature control (recooler) on each half of cryopipe \#1 and includes in each half: cryogenic enclosures, insulating vacuum, beam tube, quench stopper, bypass leads, and external connections. The beam position monitor is located on the lead end of the SPRI; each half of cryopipe \#1 may contain corrector element magnet packages. There are two each SPRI within the HEB lattice; the locations are H10 and H50. A schematic of the SPRI is shown in Figure 5. Components of the SPRI are listed in Table 6.

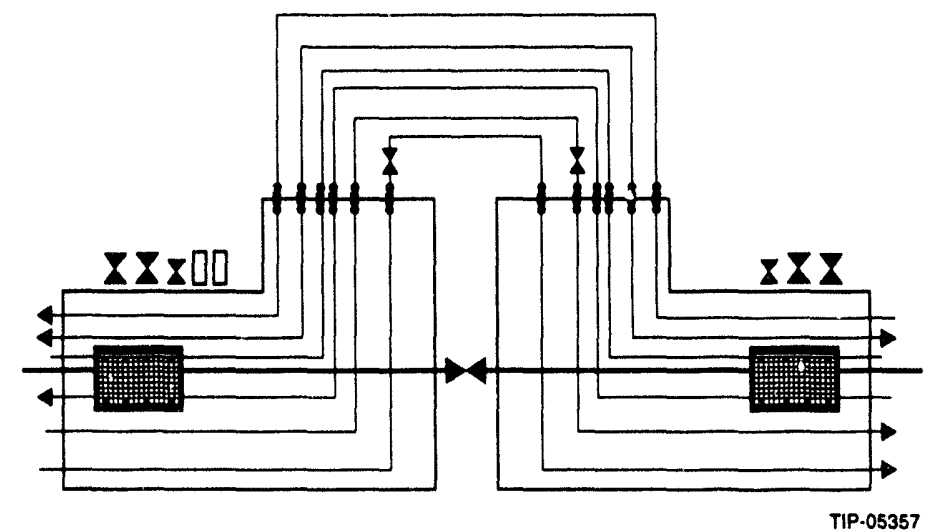

Figure 5. A schematic of the SPRI, with bayonets, cryo-valves, quench valve, recoolers, and bypass leads.

TABLE 6. SPRI COMPONENTS.

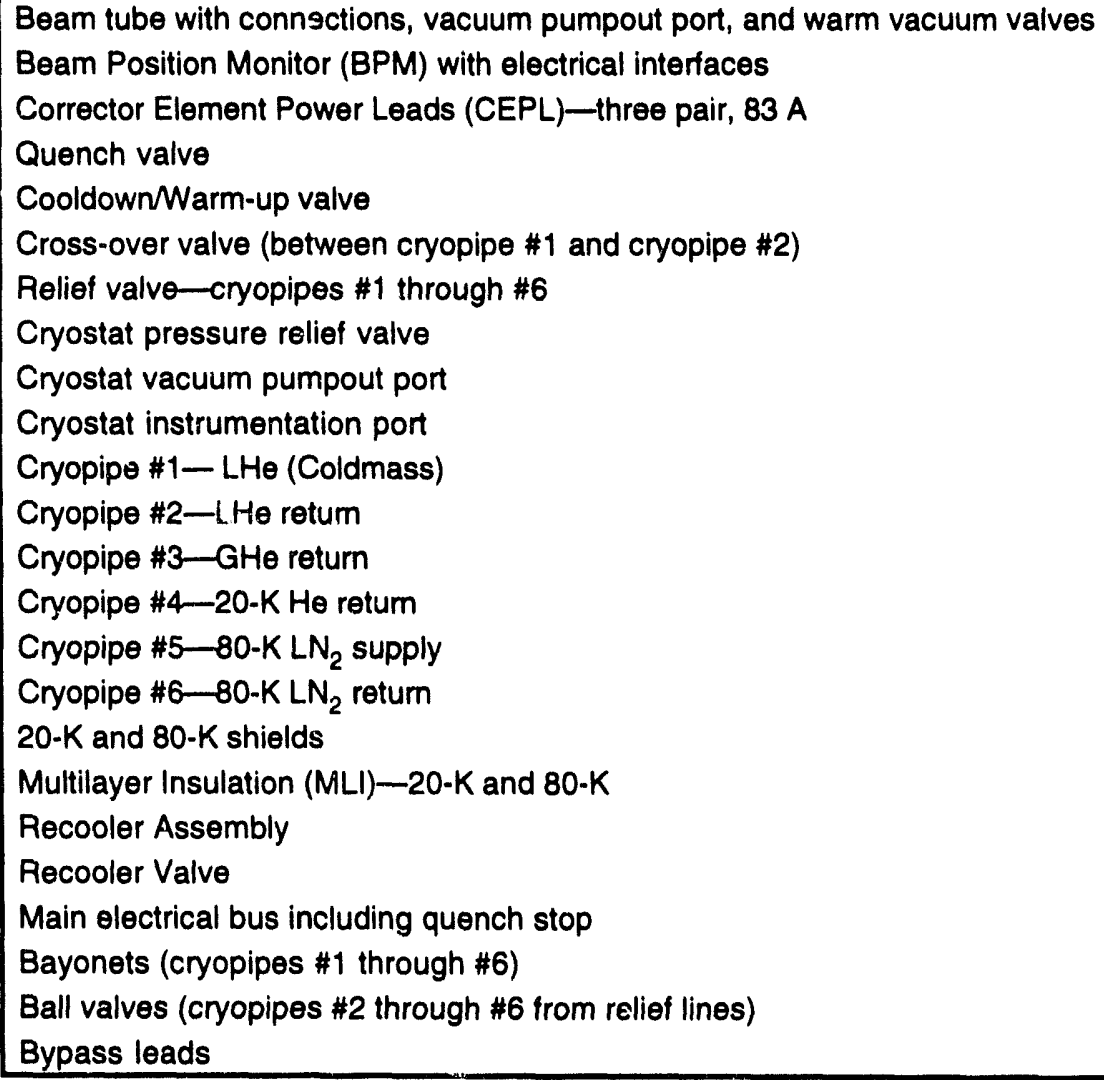




\subsection{Spool Piece with Recooler and $3 \mathrm{~m}$ of Length for Cryogenic Isolation (SPR3I)}

The SPR3I provides cryogenic and vacuum isolation; also designed within the SPR3I is turnaround capability of the cryogenics for each string via the cryogenic bayonets. The dividing of the string allows for two distinct cryogenic sections. The cryopipes may be isolated by the bayonets. Cryopipes \#5 and \#6 are connected to a nitrogen recooler. The main magnet bus is partitioned between each half of the SPR3I. The SPR3I also contains liquid temperature control (recooler) on each cryopipe \#1 and includes in each half: cryogenic enclosures, insulating vacuum, beam tube, bypass leads, and external connections. The beam position monitor is located on the lead end; each half of cryopipe \#1 may contain corrector element magnet packages for the SPR3I. There are two each SPR3I within the HEB lattice; the locations are H30 and H70. Figure 6 depicts a schematic of the SPR3I. Table 7 lists the components of the SPR3I.

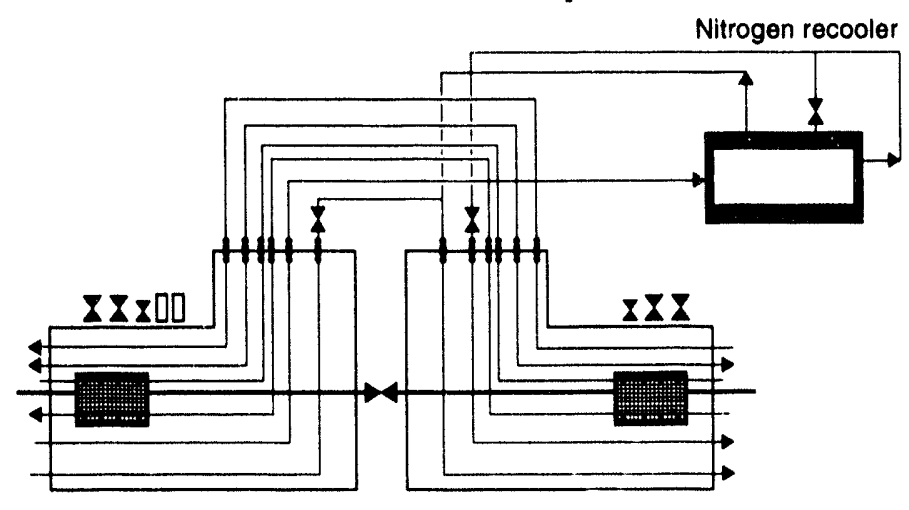

TIP-05358

Figure 6. A schematic of the SPR3I, with bayonets, cryo-valves, quench valve, and recoolers.

TABLE 7. SPR3I COMPONENTS.

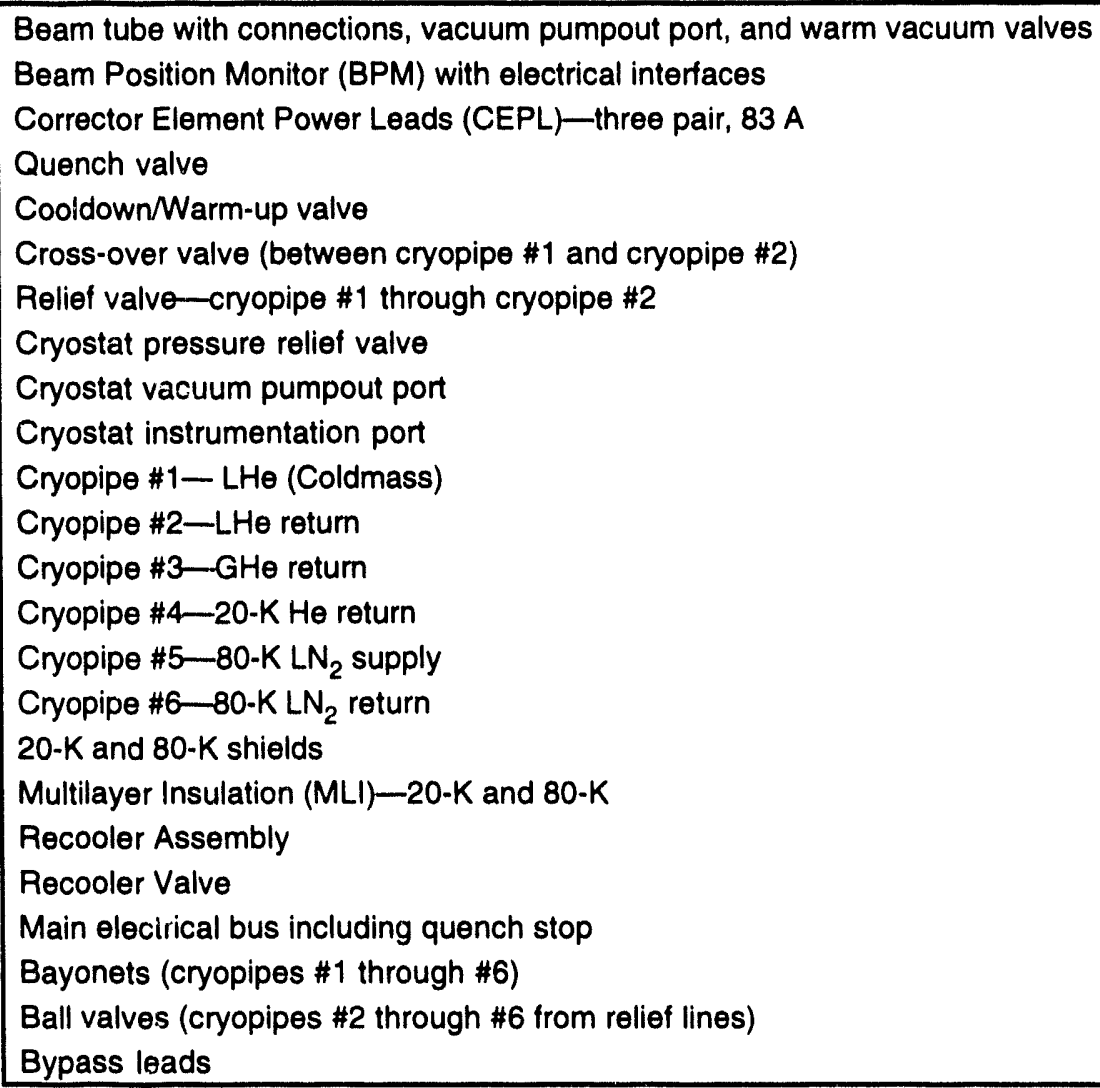




\subsection{Spool Piece with Recooler and $4 \mathrm{~m}$ of Length for Cryogenic Transition (SPR4T)}

The SPR4T provides a connection system for prower, cryogenics, vacuum, and instrumentation. The SPR4T includes cryogenic enclosures, insulating vacuum, beam tube, beam position monitor, external connections, and corrector element magnet packages. The SPR4T provides the magnet quench protection system (quench stopper and bypass leads) and liquid temperacure control (recooler). Also, the SPR4T is designed with a cryogenic side access port (sap) on one end to redirect the cryogenic flow to a bypass box. The SPR4T has a cold main bus encased within a LHe tube, which exits the cryopipe \#1 (coldmass) end plate, and routed through the cryogenic sap. The SPR4T is positioned to the left of the superconducting quadrupole magnets in the bypass regions of the HEB lattice. There are six each SPR4T within the HEB lattice; the locations are $\mathrm{H} 10, \mathrm{H} 20, \mathrm{H} 40, \mathrm{H} 50, \mathrm{H} 60$, and $\mathrm{H} 80$. Figure 7 depicts a schematic of the SPR4T. Table 8 lists the components of the SPR4T.

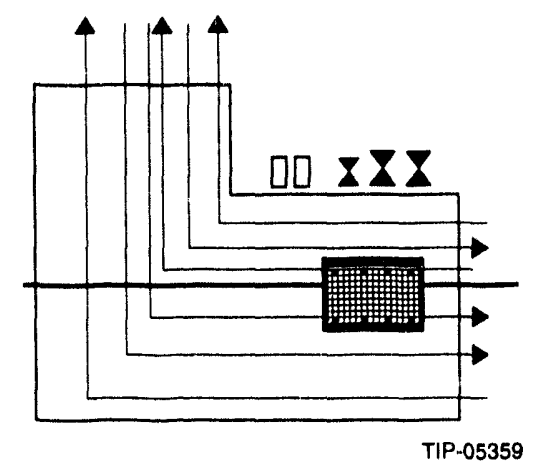

Figure 7. A schematic of the SPR4T, with cooldown and warm-up valve, quench valve, recooler, and bypass leads.

TABLE 8. SPRAT COMPONENTS.

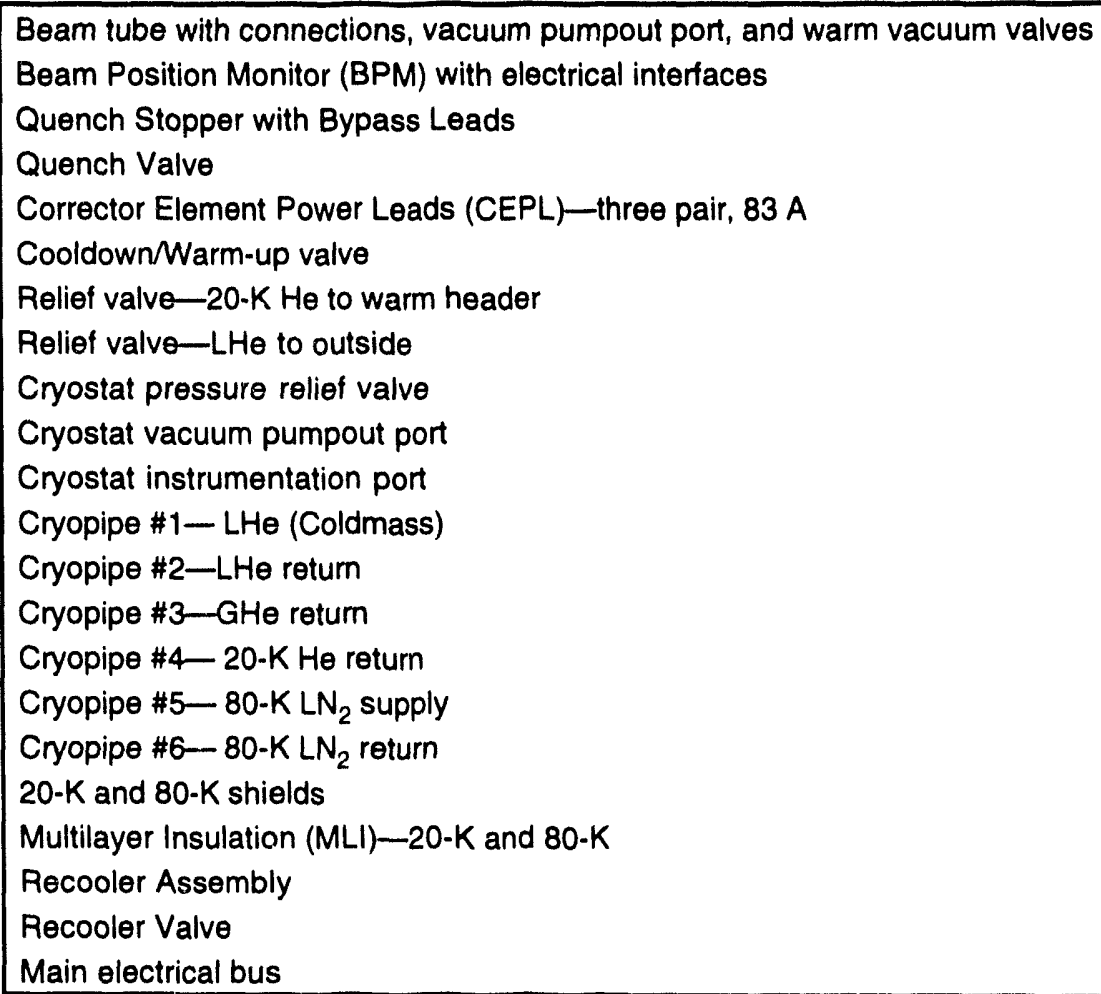




\subsection{Spool Piece without Recooler and $1 \mathrm{~m}$ of Length for Cryogenic Return (SPX1R)}

The SPX1R provides a turnaround for the cryogenics and power bus in the bypass region of the West Long Straight. The beam tube is designed to make a cold-to-warm transition within the SPX1R. The SPXIR includes cryogenic enclosures, insulating vacuum, beam tube, and external connections. There are four each SPX1R within the West Long Straight at H10. Figure 8 depicts a schematic of the SPX1R. Table 9 lists the components of the SPX1R.

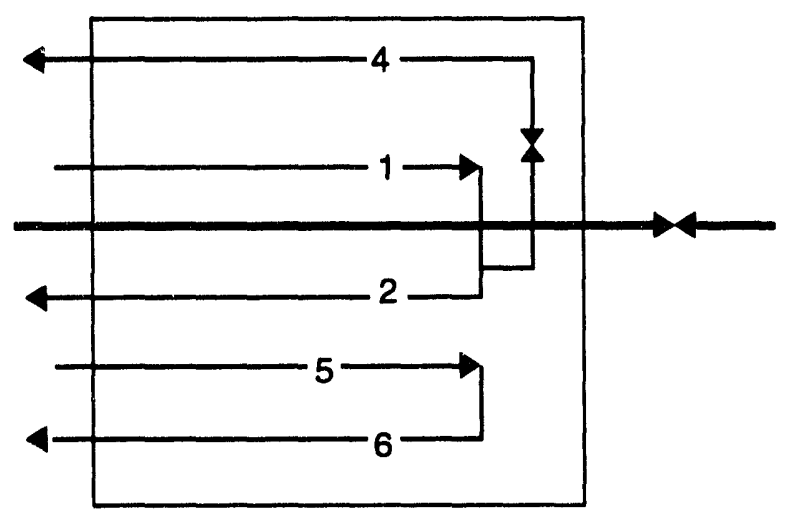

TIP. 05360

Figure 8. A schematic of the SPX1R, with cryopipes In a turnaround configuration.

TABLE 9. SPX1R COMPONENTS.

Beam tube with cold-to-warm transition
Cryostat pressure relief valve
Cryostat vacuum pumpout port
Cryostat instrumentation port
Cryopipe \#1- LHe (Coldmass)
Cryopipe \#2-LHe return
Cryopipe \#4-20-K He retum
Cryopipe \#5-80-K $\mathrm{LN}_{2}$ supply
Cryopipe \#6-80-K $\mathrm{LN}_{2}$ return
20-K and $80-\mathrm{K}$ shields
Multilayer Insulation (MLI)-20-K and $80-\mathrm{K}$
Main electrical bus




\subsection{Spool Piece without Recooler and $1 \mathrm{~m}$ of Length for Cryogenic Transition (SPX1T)}

The SPX1T provides a transition for the cryogenics and power bus in the bypass region of the West Long Straight. The beam tube is designed to make a cold-to-warm transition in the SPX1T and the superconducting electrical bus is designed to be routed within the LHe supply (cryopipe \#1) and exit via the LHe return (cryopipe \#2). The SPX1T includes cryogenic enclosures, insulating vacuum, beam tube, and external connections. There are seven each SPX1T located within the West Long Straight at H10. Figure 9 depicts a schematic of the SPX1T. Table 10 lists the components of the SPX1T.

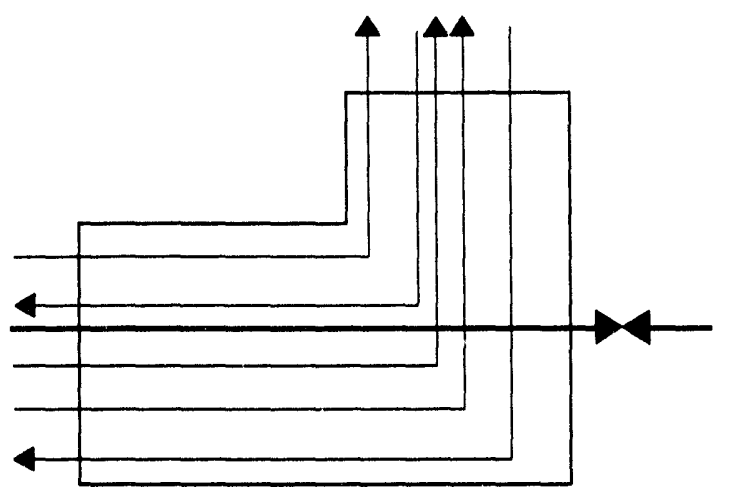

TIP-05361

Figure 9. A schematic of the SPX1T, with cryoplpes and transition.

TABLE 10. SPX1T COMPONENTS.

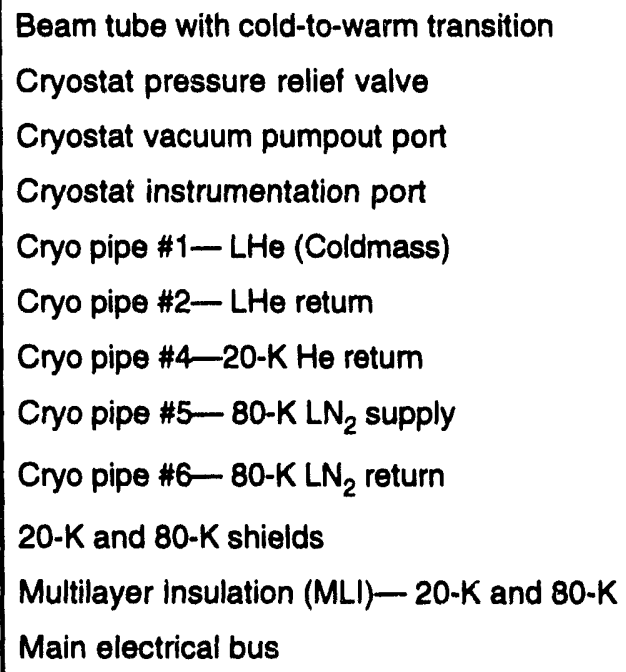




\subsection{SPECIALIZED HEB SPOOL PIECES-SUPERSPOOL}

The HEB supetspool is the design proposal ${ }^{3,4}$ that combines a superconducting HEB quadrupole magnet into a common cryostat with the adjacent spool piece. There exists within the HEB lattice many combinations of quadrupole magnets and spool pieces. The combination of HEB quadrupole magnets with adjacent spool pieces would conserve linear space and provide much needed real estate for correction packages or other HEB lattice components.

The combination of the HEB quadrupole magnets and the spool pieces will enclose cryopipe \#1 (coldmass) of the quadrupole magnets with cryopipe \#1 (coldmass) of the spool pieces, using a common flange connection. The design of the cryopipes may incorporate continuous tubes throughout the common cryostat. The superspool design incorporates common beam tube, thermal shields, and MLI blankets. Figure 10 depicts a cross-sectional view of the superspool with the outer cryostat removed for clarity. The HEB quadrupole magnet is displayed on the left and is contained within the quadrupole magnet coldmass. Note the flange-type transition between the two coldmasses. The spool piece depicted here is the SPXA. There are three support posts within the superspool.

One slide post is shown supporting the quadrupole magnet; the remaining fixed and slide posts are shown supporting the spool piece coldmass with assorted correction elements enclosed. The vacuum barrier is shown adjacent to the fixed post, and the quench stopper housing is shown at the return end of the SPXA.

There are four types of superconducting HEB quadrupole magnets positioned throughout the HEB lattice. Seven spool pieces as identified from Table 1, excluding the SPX1R and the SPX1T, are proposed in design to be combined with a given quadrupole magnet to produce the superspool.

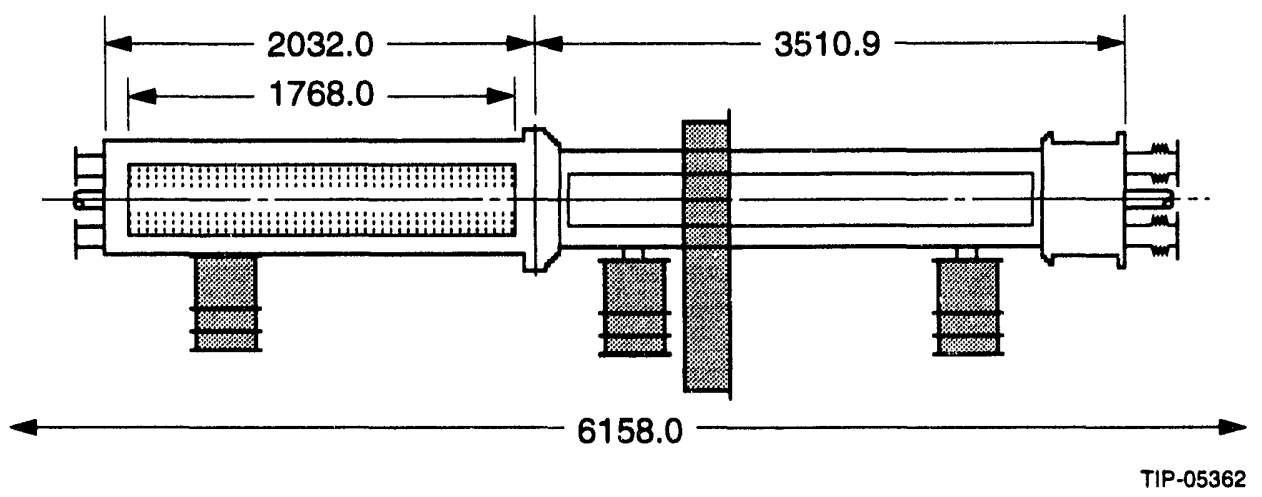

Figure 10. Internal cross section of HEB superspool. (Dimensions are in $\mathrm{mm}$.) 


\subsection{CONCLUDING REMARKS}

The SSC HEB spool pieces and the components of those pieces have been identified. There have been many design iterations with the HEB spool pieces to minimize configurations and quan tities. Components of the HEB spool pieces are designed and held as models to be added as assemblies to the specific HEB spool piece as design information is made available.

The status of each HEB spool per Table 1 has been documented, ${ }^{5}$ and each of these spool pieces may be identified with a partial completion of the standard spool piece model. There are no released HEB spool piece drawings, and there are no assigned drawings numbers for the HEB spool pieces excepting for the SPXA and the SPRA top assembly drawings. Each HEB spool piece model is contained within the HP-UGII format and is stored under the file name COBRA/EXPORT/HOME/STRUBE.

HEB spool piece designations ${ }^{6}$ have been proposed to distinguish the HEB spool pieces from the Collider spool pieces. Figure 11 depicts the proposed nomenclature.

The HEB spool pieces are functional and physical interfaces to the other accelerator subsystems. They are integral components of the accelerator system, and the performance of all spool pieces is critical to the operation of the tccelerator. All spool pieces must be designed to function and to support sustained accelerator operations.

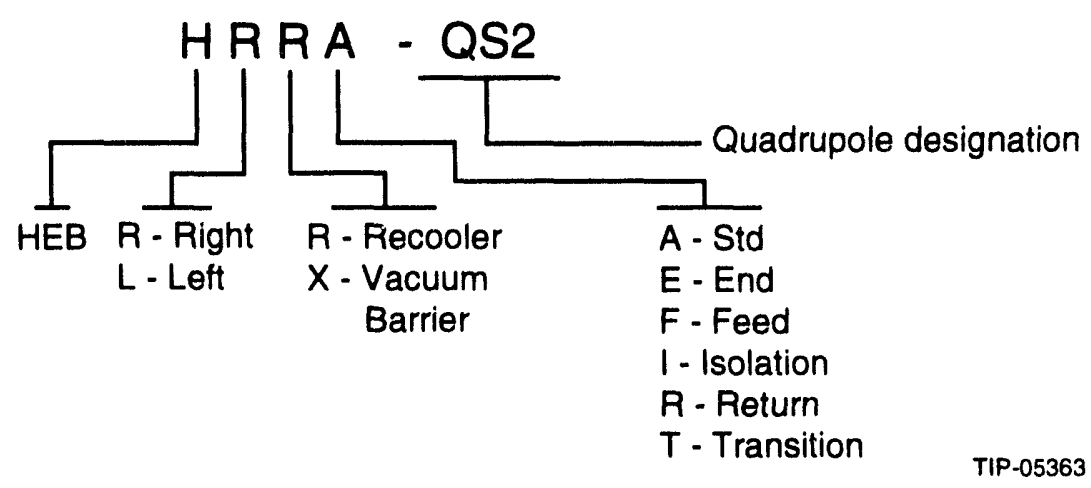

Figure 11. HEB proposed designations.

\section{ACKNOWLEDGMENTS}

The authors wish to thank A. Scheidemantle, R. Smellie, P. Kocur, and T. Clayton of the SSC Laboratory for their contributions to the development of these specialized HEB spool pieces. 


\section{REFERENCES}

1. D. M. Clark, HEB Spool Pieces, 27 January 1993.

2. DRAFT Element Specification (Level 3B) for the HEB Accelerator of the Superconducting Super Collider Laboratory, Number E10-000054, W.B.S. 311.

3. R. Smellie, HEB Main Quad \& Spool “Combo,” 26 May 1993.

4. Memorandum, V. Yarba from G. Dugan et al., SUPERSPOOL, 20 September 1993.

5. Memorandum, D. Strube from D. Clark, HEB Spool Pieces-Design Status, 25 January 1994.

6. Memorandum, A. Scheidemantle from D. Strube, HEB Combinations and Proposed Designations, 18 November 1993. 

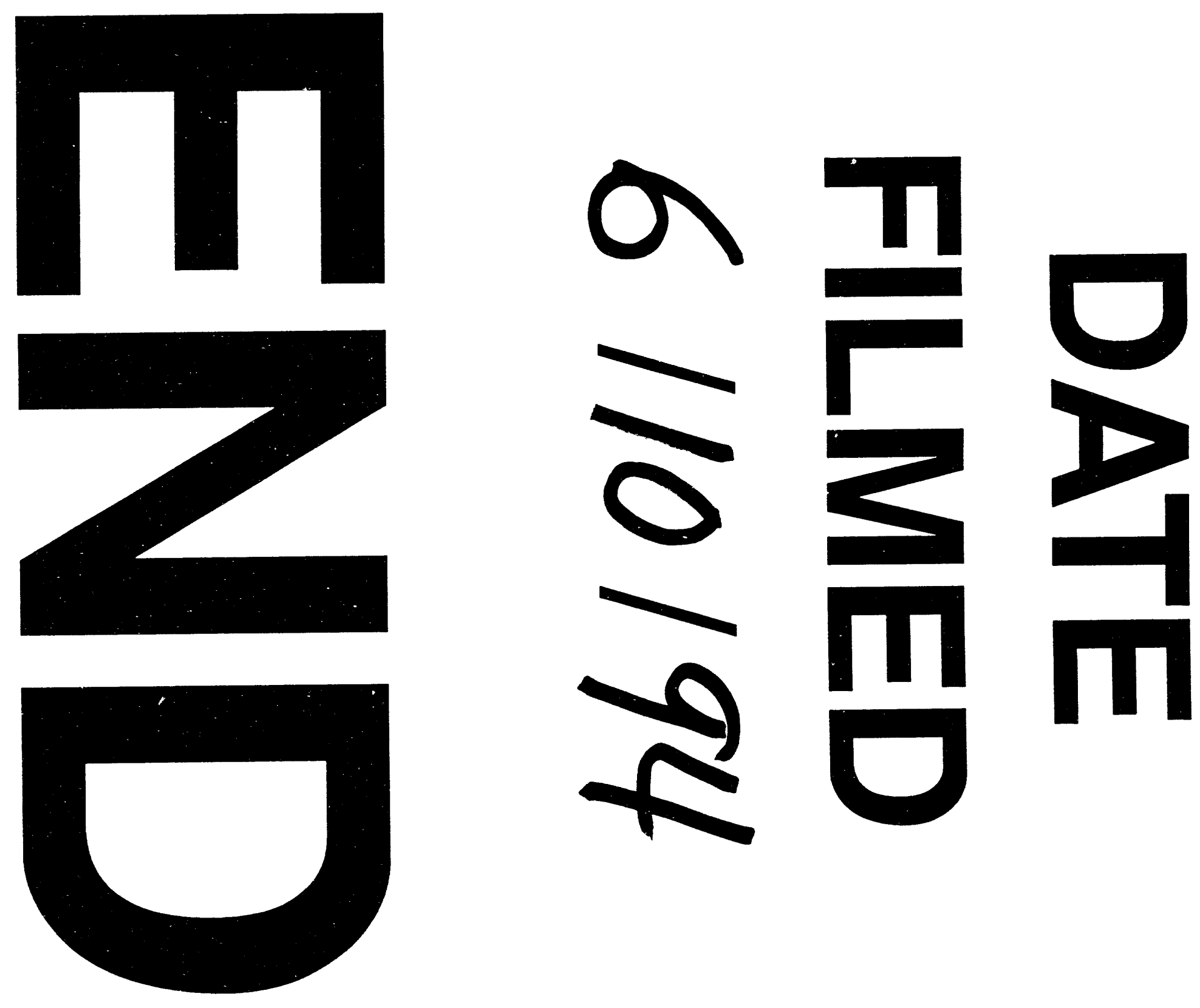
